\section{Uma abordagem metodológica de Sensoriamento Remoto para o monitoramento da contaminação do rio Paraopeba pós-desastre de Brumadinho-MG}

\author{
A Remote Sensing methodological approach for monitoring the \\ contamination in Paraopeba River after the disaster in Brumadinho-MG
}

\section{Neison Cabral Ferreira Freire' ${ }^{1}$, Admilson da Penha Pacheco" ${ }^{\prime \prime}$, Vinícius D'Lucas Bezerra Queiroz' ${ }^{1}$ (i)}

'Fundação Joaquim Nabuco, Instituto de Pesquisas Sociais, Centro Integrado de Estudos Georreferenciados para a Pesquisa Social, Recife, PE

"Universidade Federal de Pernambuco, Centro de Tecnologia, Departamento de Engenharia Cartográfica, Recife, PE

\section{RESUMO}

Este artigo tem o objetivo de apresentar e discutir o monitoramento por Sensoriamento Remoto do deslocamento da lama ocasionado pelo colapso da barragem de rejeitos de mineração do Córrego do Feijão, ocorrido em 25 de janeiro de 2019, na área rural do município de Brumadinho, Estado de Minas Gerais, Brasil. Esse evento foi classificado como um dos maiores desastres tecnoindustriais do Brasil, colocando em risco de contaminação uma das maiores e mais populosas bacias hidrográficas brasileiras: a bacia do rio São Francisco. A área de estudo compreendeu desde o local de contato da lama com a margem direita do rio Paraopeba até a sua foz na Represa de Três Marias, totalizando aproximadamente $315 \mathrm{~km}$. Para esse monitoramento foi utilizado o método de razões de bandas espectrais de imagens dos sensores MSI/Sentinel-2 e OLI/Landsat-8 de diferentes datas, empregando-se a uniformização de médias e variâncias para compatibilizar as amplitudes dos valores de reflectância de superfície em cada imagem.

Palavras-chave: Brumadinho; Desastre; Sensoriamento Remoto da água

\section{ABSTRACT}

The following article aims to present and discuss the monitoring, through Remote Sensing, of the dirt displacement caused by the collapse of the Córrego do Feijão's dam I of mining waste, which occurred on January 25, 2019, in the rural area of Brumadinho, a city located in the state of Minas Gerais, Brazil. This 
event is considered one of the greatest technoindustrial disasters in Brazilian history, placing in danger one of the largest hydrographic basin in Brazil: the São Francisco river basin. The search area comprises from where the sludge mud got in contact with the Paraopeba's right bank to its mouth into the Três Marias Dam, adding up to approximately $315 \mathrm{~km}$. For this monitoring the spectral band ratio method was utilized, using images from the sensors MSI/Sentinel-2 and OLI/Landsat-8 captured at different dates, employing standardization of means and variances to harmonize the range of the surface reflectance values in each image.

Keywords: Brumadinho; Disaster; Water Remote Sensing

\section{INTRODUÇÃO}

De acordo com Barbosa et al. (2019), os sistemas aquáticos, em consequência da pressão antrópica e poluição hídrica, apresentam-se em constante vulnerabilidade, sendo sensíveis às alterações ambientais e climáticas. O monitoramento de parâmetros biofísicos é um dos meios de compreender os processos naturais e antrópicos que interferem na dinâmica natural destes sistemas, sendo que a alteração do estado trófico e da composição das massas de água pode inviabilizar o uso desse recurso natural (BARBOSA et al., op. cit.).

Estudos de qualidade da água em sistemas aquáticos continentais que envolvem as suas propriedades físicas, químicas e biológicas são comumente realizados e monitorados a partir de coleta de dados limnológicos em campo e análise em laboratório. Entre as variáveis limnológicas utilizadas na avaliação da qualidade da água, as quais são diretamente influenciadas pelo uso do solo na bacia de drenagem, destacam-se as concentrações de fósforo, nitrogênio, oxigênio dissolvido e clorofila-A, bem como os valores de $\mathrm{pH}$, turbidez e densidade de coliformes fecais e totais (MAROTTA et al., 2008). Segundo estes autores, a relevância do monitoramento limnológico necessita da inserção de investigação científica que pode ser amplamente apoiada pelos dados coletados.

As dificuldades de amostragem sucessivas e integradas constituem um obstáculo significativo para monitorar e gerenciar a qualidade da água (LIMA et al., 2019). De acordo com Duan et al. (2013), as medições de campo dos métodos de monitoramento limnológicostradicionais, apesar de oferecerem alta precisão, exigem muito trabalho e são 
bastantes lentas, dificultando a criação de banco de dados simultâneo sobre aspectos qualitativo da água em escala regional. Acrescente-se, ainda, que os métodos convencionais de amostragem pontual não são capazes de identificar as variações espaciais ou temporais na qualidade da água, o que é vital para a avaliação e gestão abrangente dos corpos hídricos (LIMA et al., op. cit.).

Sendo assim, o Sensoriamento Remoto, devido aos seus aspectos espacial, multiespectral e multitemporal, surge como uma alternativa científica, tecnológica e fundamental para a análise e monitoramento de parâmetros biofísicos e da qualidade da água em oceanos, rios, lagos e reservatórios. A multitemporalidade desse tipo de dado é um recurso significativo para identificar as mudanças ocorridas na mesma região da superfície terrestre em diferentes datas, destacando-se a importância e o crescimento de estudos multitemporais utilizando imagens de Sensoriamento Remoto (BITENCURTI,2017).

Nesse sentido, por exemplo, estudos sobre a variação temporal do albedo a partir de imagens de satélites foram conduzidos por Melo e Souza (2016) que demonstraram a capacidade dos sensores orbitais em possibilitar a estimação e a cartografia das mudanças nos padrões de reflectância dos alvos por meio do cálculo das interações entre a energia eletromagnética e os objetos presentes na superfície terrestre.

Em ambientes aquáticos, o Sensoriamento Remoto tem como um dos objetivos principais mapear a variabilidade espacial de parâmetros de qualidade da água. As inferências sobre os constituintes presentes na água são realizadas a partir das mudanças que as massas d'água causam no campo de luz solar que, ao incidir e penetrar na superfície da água, propaga-se na coluna d'água e, eventualmente, uma fração retorna e emerge da superfície, interagindo com a atmosfera e sendo captada pelo sensor óptico orbital (BARBOSA et al., op. cit.).

De acordo Jensen (2000), as técnicas de processamento digital de imagens envolvem a manipulação numérica e estatística de dados de uma cena através de aplicações multiescala, multitemporal e multiespectral, para reconhecimento de padrões, modelagem, e interpretação de imagens de Sensoriamento Remoto. As contribuições 
desta ciência em sistemas aquáticos são muito abrangentes, pois permitem a investigação de substâncias específicas dissolvidas ou em suspensão a partir da análise de suas respostas espectrais, gerando novas perspectivas para estudos quantitativos da qualidade água (JENSEN, 2000; JENSEN, 2009).

Jensen (2009) ainda relata que o fluxo de radiação refletido pela coluna d'água nas faixas espectrais do visível e infravermelho próximo detectado pelos sensores remotos é responsável pelas fisionomias mais claras destes cursos d’água, devido aos sedimentos inorgânicos e componentes orgânicos em suspensão e/ou dissolvidos. Portanto, o aumento da concentração do particulado em suspensão e substâncias dissolvidas é diretamente proporcional ao aumento da magnitude do fluxo radiante captada pelo sensor óptico orbital nessas faixas do espectro, o que demonstra a utilidade destas regiões do espectro eletromagnético (EEM) (verde, vermelho e infravermelho próximo) para a detecção de mudanças em corpos hídricos superficiais.

Estudos da qualidade da água por Sensoriamento Remoto foram desenvolvidos inicialmente a partir de dados dos sensores TM1, TM2, TM3 e TM4 da série Landsat nas décadas de 80 e 90 do século passado (LILLESAND et al., 1983; CATS et al., 1985; CASELES et. al., 1986; NOVO e TUNDISI, 1988; MITTENZWEY et. al., 1992). Desde então, outros estudos têm sido realizados a partir da análise de parâmetros biofísicos e físico-químicos, tais como: transparência, turbidez, carbono orgânico particulado, clorofila-A e sólidos suspensos totais.

As informações registradas por sensores imageadores e não imageadores, orbitais, aéreos e/ou terrestres são extremamente importantes na identificação dos constituintes opticamente ativos (COAs). Estes podem ser considerados todos aqueles elementos que alteram as propriedades ópticas inerentes da água e envolvem os sólidos em suspensão, os pigmentos fotossintetizantes (clorofila), e a matéria orgânica dissolvida colorida e a própria molécula d'água (RUDORFF et al., 2007; Barbosa et al., op. cit.). Nesse sentido, os efeitos dos COAs sobre o comportamento espectral da água têm sido abordados na 
literatura, como por exemplo, nos trabalhos de Rudorff et al. (2007), Gitelson et al. (2011), Pereira et al. (2011) e Le et al. (2013). Além disso, pesquisas relacionadas ao desenvolvimento de algoritmos e/ou modelos a partir de dados de Sensoriamento Remoto orbital para monitorar o estado trófico da água em diferentes ecossistemas aquáticos do mundo também foram realizados por diversos autores (LILLESAND et al., 1983; LATHROP et al., 1991; CHEN, et al., 2007; DOXARAN et al., 2009; GILTELSON et al., 2009b; DOÑA, et al., 2014).

A temática que envolve esta pesquisa foi o rompimento da Barragem de Rejeitos de Mineração de Brumadinho-MG que colapsou de forma abrupta no dia 25 de janeiro de 2019. Neste evento, cerca de 12 milhões de $\mathrm{m}^{3}$ de lama de rejeitos de mineração espalharam-se e se depositaram na superfície do terreno ao longo da drenagem do ribeirão Ferro-Carvão, destruindo inúmeras construções, estradas, casas, lavouras e vidas. Uma parte desses rejeitos atingiu a margem direita do rio Paraopeba em menos de $24 \mathrm{~h}$ após o rompimento da barragem e, partir desse contato, os rejeitos vertidos no leito do rio se diluíram e foram carreados pelo sistema lótico até atingir o lago da pequena Usina Hidrelétrica (UHE) de Retiro Baixo, de propriedade do Sistema Furnas-Cemig, no município de Pompéu-MG, trinta e quatro dias após o desastre. Embora a maior parte do material contaminante vertido no rio tenha sido contida pelo lago da UHE, uma parte provavelmente extravasou o barramento através da única turbina em operação, estimando-se, por meio de imagens satélites, a sua chegada à foz do Paraopeba na Represa de Três Marias no dia 12 de março de 2019.

O risco da contaminação do rio São Francisco, que tem o rio Paraopeba como um de seus principais afluentes, motivou uma pesquisa emergencial da qual este artigo é parte integrante, objetivando o monitoramento do deslocamento da lama de rejeitos no curso do rio Paraopeba até a represa de Retiro Baixo, distante 27 km da sua foz na Represa de Três Marias, esta já no curso do rio São Francisco. Neste contexto, este estudo estabelece e valida uma metodologia de Sensoriamento Remoto para o monitoramento 
desta contaminação após o desastre de Brumadinho-MG, a partir de dados de reflectância de superfície obtidos através dos sensores orbitais MSI/Sentinel-2 e OLI/Landsat-8 de diferentes datas, utilizando técnicas de aritmética de bandas e uniformização de médias e variâncias, como será detalhado adiante.

\section{MATERIAIS E MÉTODOS}

\section{1 Área de estudo}

A área de estudo envolve o município de Brumadinho, localizado na Região Metropolitana de Belo Horizonte-MG, e o rio Paraopeba que banha o estado de Minas Gerais. De acordo com o Instituto Mineiro de Gestão das Águas (IGAM) (2005), a extensão do rio Paraopeba é de 510 km e sua bacia cobre 13.643 km² e 35 municípios. A sua foz está localizada na Represa de Três Marias e os seus principais afluentes são o rio Macaúbas, o rio Camapuã, o rio Betim, o rio Manso e o ribeirão Serra Azul.

Os principais usos da água da bacia do rio Paraopeba são: geração de energia elétrica, consumo humano, abastecimento industrial, mineração e irrigação (CPRM, 2019), além da pesca artesanal e dessedentação animal. A bacia do rio Paraopeba tem área de drenagem da ordem de $13.640 \mathrm{~km}^{2}$ (CPRM, 2019). A figura 1 ilustra a espacialização do Rio Paraopeba e da barragem que se rompeu, bem como sua relação com a bacia hidrográfica do São Francisco.

Figura 1 - Mapa de Localização da região do desastre de Brumadinho, do rio Paraopeba e sua relação com a bacia do rio São Francisco 


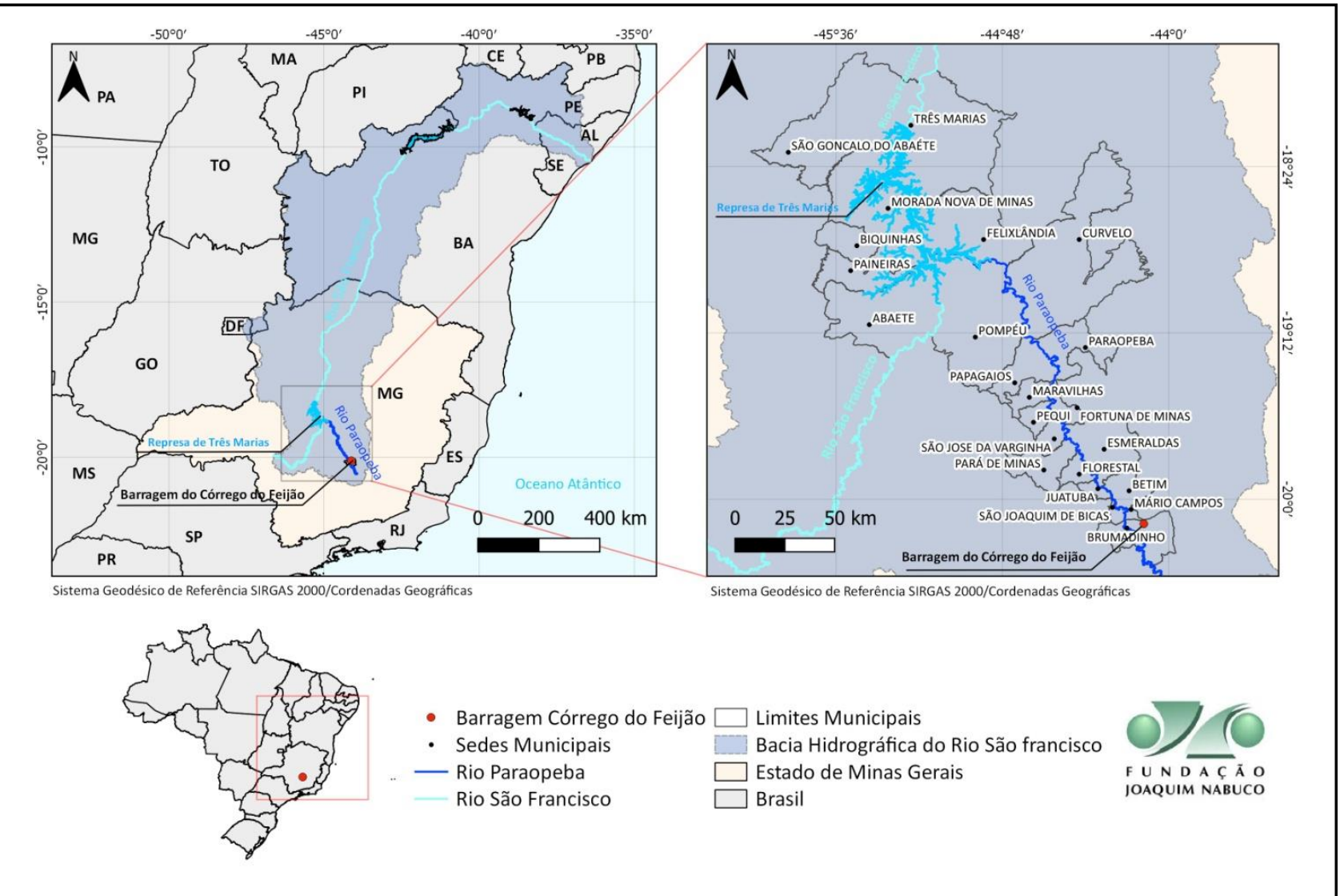

Fonte: Autores, 2019

\subsection{Procedimentos metodológicos}

Considerando que a massa de rejeitos em contato com o corpo hídrico adicionou significativos aportes de COAs, elevando assim sua turbidez, espera-se, de acordo com a literatura referenciada, um aumento de reflectância de superfície das bandas espectrais do visível e do infravermelho próximo nas áreas atingidas registradas pelos sensores ópticos orbitais e disponibilizadas através das imagens de satélites adquiridas após o desastre. Partindo desse princípio, adotou-se uma metodologia que utiliza dados das bandas correspondentes a essa variação de reflectância ocasionada pelo aumento da turbidez.

Diante dos distintos métodos de processamento de imagens que poderiam ser utilizados para a detecção de mudanças na superfície terrestre, a pesquisa adotou o 
método de razão de bandas após uniformização de médias e variâncias de imagens para identificar as mudanças ao longo do curso do rio ocasionadas pelo desastre.

A metodologia para o mapeamento do deslocamento da contaminação no rio Paraopeba foi realizada a partir da definição de oito procedimentos, conforme a figura 2. O primeiro deles consistiu no processo de aquisição e tratamento de imagens de sensores ópticos orbitais.

Figura 2 - Fluxograma contendo os procedimentos metodológicos da pesquisa

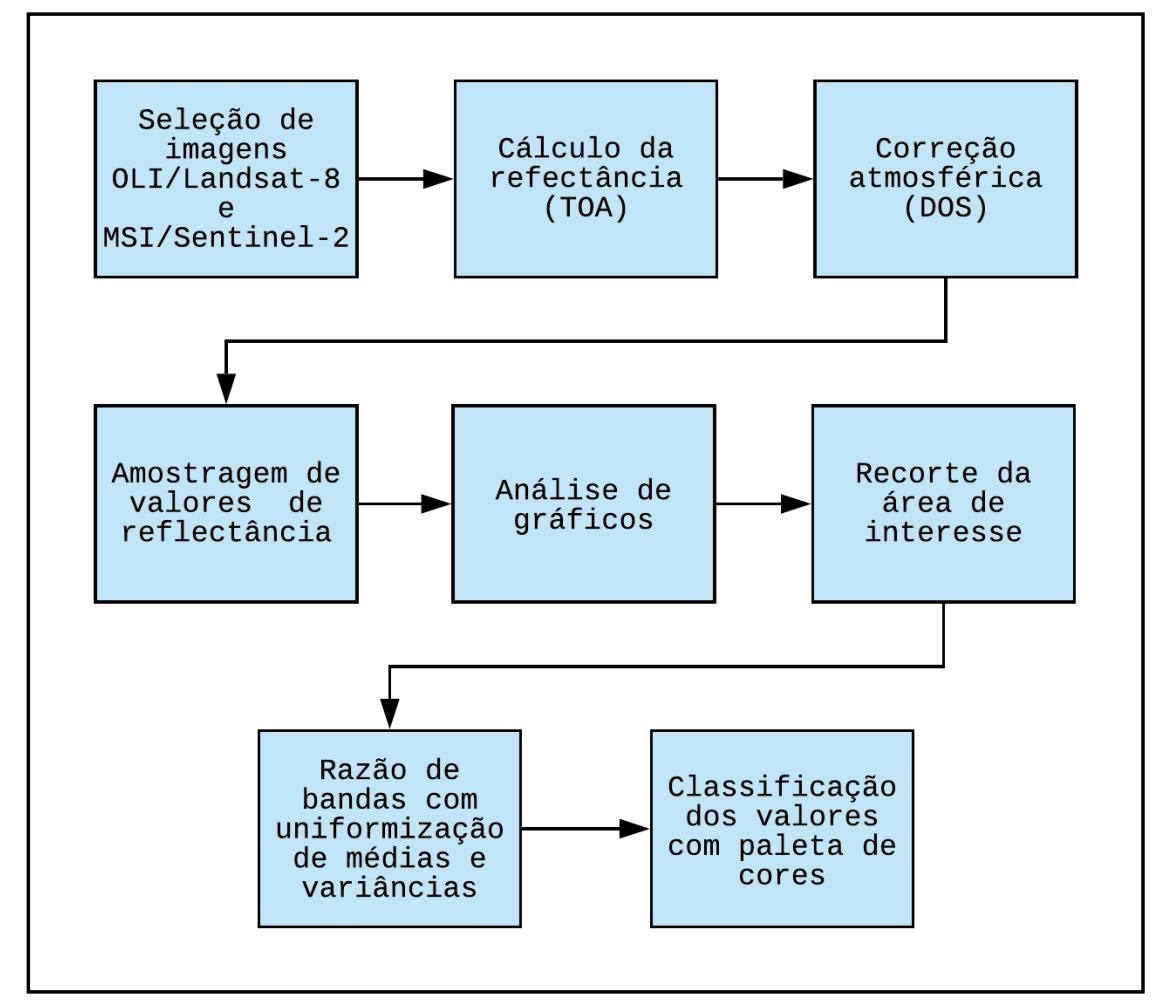

Fonte: Autores, 2019

A seleção e aquisição de imagens foi realizada nos catálogos do USGS (United States GeologicalSurvey) (2019) e do CopernicusScihub, repositório de imagens da Agência Espacial Europeia (ESA) (2019), sendo utilizados, respectivamente, os sistemas sensores OLI/LandSAT-8 e MSI/SENTINEL-2 ao longo de uma série temporal entre 14 de janeiro e 08 de março de 2019. As datas puderam ser definidas a partir do conhecimento do momento "antes" e "após" o desastre de Brumadinho que, associadas à resolução temporal de cada 
sensor, permitiram o monitoramento do avanço da contaminação por revisita à mesma área observada e, consequente, a comparação com imagens de datas anteriores ao colapso da barragem.

O período chuvoso da época do desastre foi um elemento que dificultou a aquisição de imagens úteis para a extração de informações devido à presença constante de nuvens, tornando-se necessário o monitoramento diário dos catálogos em busca de janelas meteorológicas. Apesar disso, foram selecionadas imagens que apresentaram boas condições de processamento com foco nas áreas sem cobertura de nuvens ao longo do curso do rio Paraopeba (Quadro 1).

Quadro 1 - Datas de aquisição de imagens e respectivos satélites/sensores

\begin{tabular}{|l|c|c|}
\hline \multicolumn{1}{|c|}{ Data } & Satélite & Sensor \\
\hline $14 / 01 / 2019$ & LandSAT-8 & OLI \\
\hline $17 / 01 / 2019$ & Sentinel-2 & MSI \\
\hline $22 / 01 / 2019$ & Sentinel-2 & MSI \\
\hline $27 / 01 / 2019$ & Sentinel-2 & OLI \\
\hline $30 / 01 / 2019$ & LandSAT-8 & MSI \\
\hline $01 / 02 / 2019$ & Sentinel-2 & OLI \\
\hline $22 / 02 / 2019$ & LandSAT-8 & MSI \\
\hline $08 / 03 / 2019$ & Sentinel-2 & \\
\hline
\end{tabular}

As imagens foram processadas nos softwares livres Spring 5.5.5 e o QGIS 2.18.26. Todos os processos que envolveram cálculos matemáticos cujas equações estão apresentadas na metodologia adotada foram executados por meio de álgebra espacial utilizando a calculadora raster do software QGIS. Nesse processo, a imagem original é tratada como uma matriz, onde o mesmo cálculo é executado individualmente para cada pixel, resultando uma nova imagem.

\subsubsection{Cálculo dos parâmetros}


Os procedimentos metodológicos 2 e 3 foram definidos pelo cálculo dos parâmetros físicos. A fim de mapear o deslocamento da contaminação no rio Paraopeba, primeiramente, foi calculada a reflectância nas cenas referentes à área onde ocorreu o desastre.

Para o sistema sensor OLI/LandSAT-8, segundo a USGS (2019), a conversão de número digital para reflectância no topo da atmosfera (TOA) é calculada segundo as equações 1 e 2.

$$
\begin{aligned}
& \rho_{\lambda}^{\prime}=M_{\rho} \times Q_{c a l}+A_{\rho} \\
& \rho_{\lambda}(T O A)=\frac{\rho_{\lambda}^{\prime}}{\cos \left(\theta_{S E}\right)}
\end{aligned}
$$

Na qual,

$\rho_{\lambda}^{\prime}$ : Reflectância planetária no topo da atmosfera sem correção do ângulo solar;

$M_{\rho}$ : Fator de redimensionamento multiplicativo específico por banda, presente no arquivo de metadados da imagem.

$A_{\rho}$ : Fator de redimensionamento aditivo específico por banda, presente no arquivo de metadados da imagem;

$\mathcal{Q}_{\text {cal }}$ : Valores do pixel quantificados e calibrados de produtos padrão (Número digital).

$\rho_{\lambda}$ : Reflectância planetária no topo da atmosfera (TOA).

$\theta_{S E}$ : Elevação solar local, presente no arquivo de metadados da imagem.

Como o produto Level-1C do sistema sensor MSI/Sentinel-2 (ESA, 2019) disponibiliza imagens quantificadas já em reflectância no topo da atmosfera, é necessário apenas a divisão do número digital de cada pixel por um fator de quantificação presente no arquivo de metadados da imagem.

Para este sensor, o cálculo da reflectância (TOA) foi executado como segue a equação 3:

$$
\rho_{\lambda}(T O A)=\frac{D C}{\text { Quantification_Value }}
$$


Em que,

$\rho_{\lambda}$ : Reflectância no topo da atmosfera;

DC: Contador Digital (número digital);

Quantification_Value: Valor de quantificação.

Para o cálculo da reflectância de superfície é necessário realizar a correção dos efeitos da atmosfera na imagem. Segundo Centeno (2004), a maneira mais simples de estimar a parcela correspondente ao espalhamento atmosférico é buscar uma região onde teoricamente a reflectância medida deveria ser nula. Se os pixels nestas regiões tiverem valores acima de zero, estes valores são originados unicamente do espalhamento atmosférico. Então, a correção atmosférica pode ser feita diminuindo este valor de todos os pixels na imagem. Esta técnica é conhecida como DarkObjectSubtraction (DOS) e o valor do pixel mais escuro pode ser encontrado no histograma da imagem. Para Rosa (2009), esta técnica, mesmo que tenha uma precisão menor em relação às correções físicas, ainda é muito útil quando os parâmetros atmosféricos requeridos no modelo não estão disponíveis ou não são conhecidos, ajudando a aprimorar a estimativa da reflectância terrestre.

A fórmula de correção atmosférica pelo método DOS é (Equação 4):

$$
\mathrm{g}(x)=f(x)-N D_{\min }
$$

Em que $g(x)$ corresponde a imagem corrigida pelo método DOS, $f(x)$ a imagem original e $N D_{\min }$ o menor número digital encontrado no histograma da imagem.

\subsubsection{Amostragem e análise dos valores de reflectância}

O quarto procedimento metodológico adotado está relacionado à amostragem dos valores de reflectância. Geradas as imagens de reflectância de superfície, foram coletadas trinta (30) amostras de reflectância por banda para cada uma das três classes estudadas 
(água não contaminada, água contaminada e lama de rejeitos de minério), totalizando 540 valores observados (Figura 3).

Figura 3 - Imagem multiespectral da área de coleta de pontos amostrais de valores de reflectância

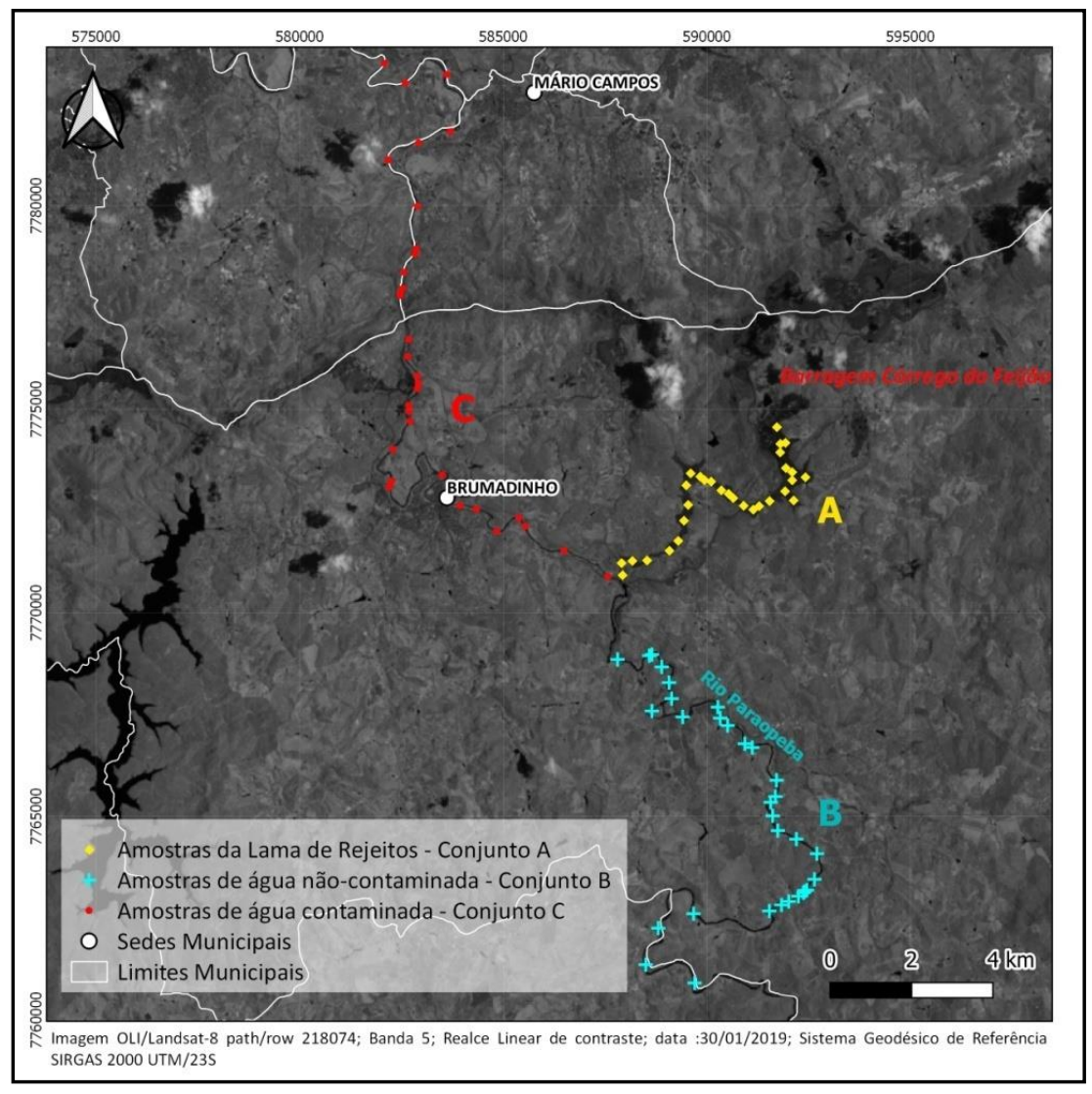

Fonte: Autores, 2019

Baseando-se na literatura citada, formulou-se a hipótese de que haveria alterações nas respostas espectrais em determinados comprimentos de onda do EEM entre os conjuntos das amostras, sendo possível identificar qual a banda de melhor resposta à presença da lama de rejeitos. Para testar a hipótese formulada, passou-se à amostragem e análise dos dados. Esta etapa consistiu na coleta dos valores de reflectância por banda para posterior verificação do comportamento espectral destas classes. Para tanto, utilizou-se a cena path/row 218/074 da data 30 de janeiro de 2019 do sensor OLI/LandSAT-8, sendo coletadas informações do leitor de pixels do software 
Spring 5.5.5 e o plugin 'point sampling tool' do software QGIS 2.18.26 . A partir destes valores foi calculada uma média aritmética simples para a plotagem da reflectância por banda de cada uma das três classes de alvos, cujos resultados podem ser observados nos gráficos da figura 4.

Figura 4 - Comportamento espectral de amostras de lama de rejeitos de mineração (amarelo), água não contaminada (azul) e água contaminada (vermelho) nas bandas 2 a 7 do sensor OLI / LandSAT-8.

\section{Comportamento espectral das amostras}

\section{Bandas 2 - 7 Landsat8/OLI}

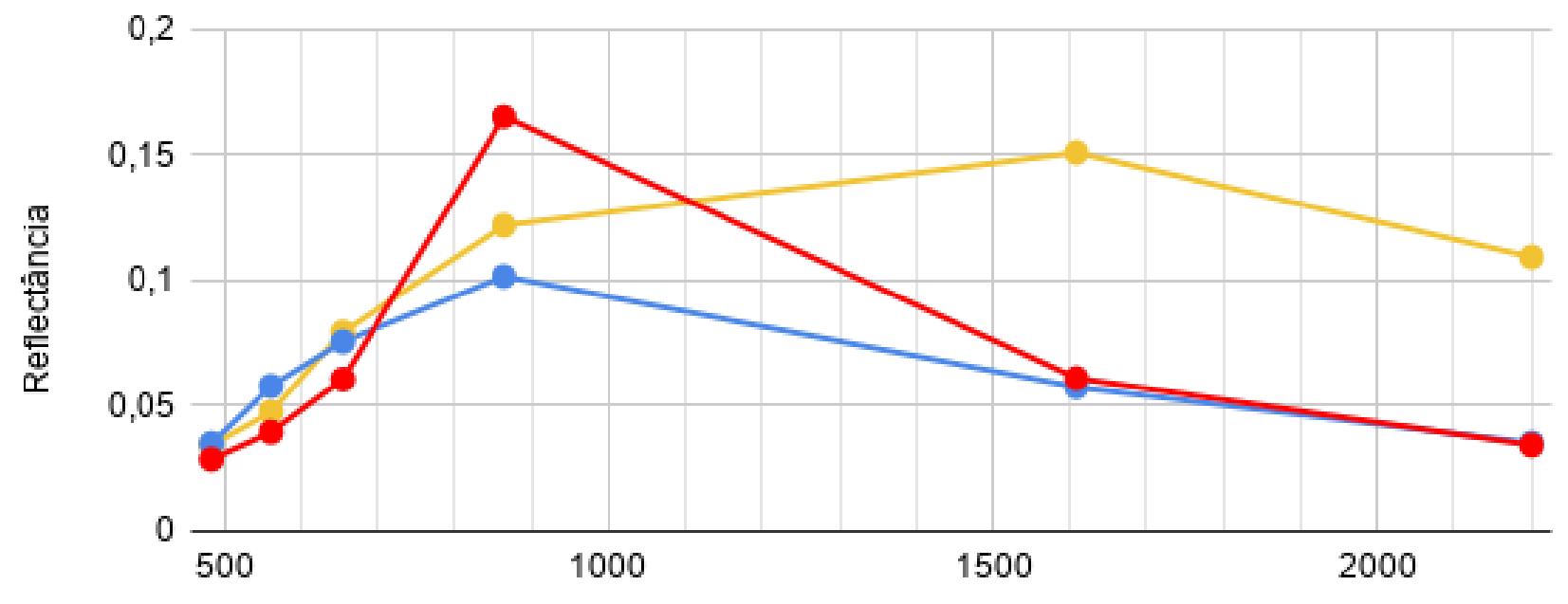

Comprimento de onda(nm)

Lama(A) Água não contaminada(B) Água contaminada (C)

Fonte: Autores, 2019

Os pontos no gráfico (figura 4) representam a posição do comprimento de onda central das bandas 2 a 7 do sensor OLI/LandSAT-8 de acordo com a tabela 1.

Tabela 1 - Comprimento de onda central das bandas 2 a 7 do sensor OLI / LandSAT-8 


\begin{tabular}{lc}
\hline Band 3 - Verde & 561 \\
Band 4 - Vermelho & 654 \\
Band 5 - Infravermelho próximo & 864 \\
Band 6 - SWIR 1 & 1609 \\
Band 7 - SWIR 2 & 2201 \\
\hline
\end{tabular}

A partir dos gráficos gerados foi possível realizar o quinto procedimento metodológico: a análise dos gráficos. Nesse sentido, observou-se que a banda que apresentou maior variação de reflectância entre os conjuntos B e C foi a banda 5 (OLI/LandSAT-8), referente a região do infravermelho próximo. Além disso, torna-se possível observar que há um comportamento espectral semelhante da banda 5, entre os conjuntos A e C, ou seja, locais onde está presente a massa de rejeitos.

Desta forma, para detectar o avanço da contaminação ao longo do curso do rio Paraopeba foi mapeada a variação de energia da banda do infravermelho próximo entre datas de aquisição de imagens antes e após o desastre, calculando a razão de bandas com uniformização de médias e variâncias (UMV).

Após análise de gráficos foram realizados recortes geográficos a fim de delimitar a área de estudo e otimizar os processamentos seguintes, passando-se ao sexto procedimento. Nessa etapa, definiu-se um recorte geográfico ao longo do curso do rio Paraopeba, desde o contato com a contaminação, no município de Brumadinho, até a represa de Retiro Baixo. Esta delimitação foi feita partir de um buffer de $200 \mathrm{~m}$ a contar do vetor linha que define o rio, disponibilizado pela Infraestrutura de Dados Espaciais do Estado de Minas Gerais (Governo de Minas Gerais, 2019). Esse valor do buffer permite abranger uma área contínua ao longo do espelho d'água e parte das margens esquerda e direita do rio Paraopeba.

Chegando à região onde se encontra a massa d'água da represa de Retiro Baixo foi gerado um recorte geográfico mais amplo, específico para o estudo desta área, tendo como base os mesmos procedimentos metodológicos apresentados nas seções anteriores. 


\subsection{Método da razão de bandas com uniformização de médias e variâncias}

Zanotta et al (2019:168) afirmam que "a divisão, também conhecida como razão de bandas, é uma das operações mais utilizadas em aplicações com imagens", sendo "capaz de realçar alvos específicos contidos nela". Ainda segundo ele, utilizam-se duas bandas que apresentem maior ou menor reflectância do alvo de interesse, após análise de suas respectivas curvas espectrais. O método aqui utilizado fez uso desse princípio, porém considerando a razão entre bandas do mesmo satélite/sensor/cena em datas distintas, em função das modificações na turbidez da coluna d'água após o desastre.

De acordo com Ferrari et al. (2011), o método da uniformização das médias e variâncias é feito por meio de transformação linear. Esta uniformização é necessária para compatibilizar os níveis de cinza dos elementos da imagem em cada banda espectral envolvida quando utilizamos dados obtidos a partir de datas distintas. .

Entretanto, para a compatibilização proposta por Ferrarri et al. (op. cit.) torna-se necessário definir uma imagem de referência como base de ajuste para todas as outras imagens da série temporal. Desta forma, ao partir para o sétimo procedimento metodológico, o estudo utilizou preliminarmente para o processo a banda 5 do sensor OLI, cena 218074, das imagens datadas de 14 e 30 de janeiro de 2019, tomando como referência a imagem do dia 14 e como imagem de ajuste a do dia 30.

Para a uniformização de médias e variâncias, adotaram-se os seguintes procedimentos (Ferrari et al., op. cit.; Marques Júnior e Sousa, 2007):

$$
\begin{aligned}
& \text { ganho }=\sqrt{\frac{\sigma^{2} R}{\sigma^{2}}} \\
& \text { offset }=\mu_{R}-\text { ganho } * \mu_{S} \\
& S^{\prime}=S * \text { ganho }+ \text { offset }
\end{aligned}
$$

Em que:

$\sigma^{2}{ }_{R}$ : Variância da reflectância da imagem de referência;

$\sigma^{2}{ }_{s}$ : Variância da reflêctância da imagem de ajuste; 
$\mu_{R}$ : Média da reflectância da imagem de referência;

$\mu_{S}$ : Média da reflectância da imagem de ajuste;

S: Imagem de ajuste e $S^{\prime}$ : Imagem ajustada.

O oitavo e último procedimento metodológico se refere ao realce de contraste dos valores calculados. Com o intuito de realçar as diferenças entre as imagens, foi realizada uma razão entre a imagem de referência e a ajustada, partindo do pressuposto de que as maiores mudanças no comportamento reflexivo do corpo d'água será obtido com valores próximos a 0. Entretanto, devido às pequenas diferenças que seriam imperceptíveis ao sistema visual humano (SVH) resultantes deste processo, foram adotados valores de 100 para ganho e 200 de offset para realce de contraste e deslocamento de média para valores digitais mais altos.

$$
S^{\prime \prime}=\left(\frac{R}{S^{\prime}}\right) * g_{a n h o}^{\prime}+\text { off } \text { set }^{\prime}
$$

em que,

$S^{\prime \prime}$ : Imagem resultado realçada;

S': Imagem ajustada;

R: Imagem de referência;

A imagem S' (figura 5) corresponde a uma imagem razão de bandas realçada que evidencia as variações da reflectância da banda do infravermelho próximo ao longo do curso do rio Paraopeba, utilizando imagens OLI/LandSAT-8.

Figura 5 - Imagem resultante após o processamento da razão de bandas uniformizadas com offset e aplicação da paleta de cores (imagem S'): na cor vermelha onde houve alterações nos constituintes opticamente ativos na água entre as datas de aquisição das imagens OLI/Landsat8 de 14 e 30 de janeiro de 2019 (em azul onde não houve alterações). 


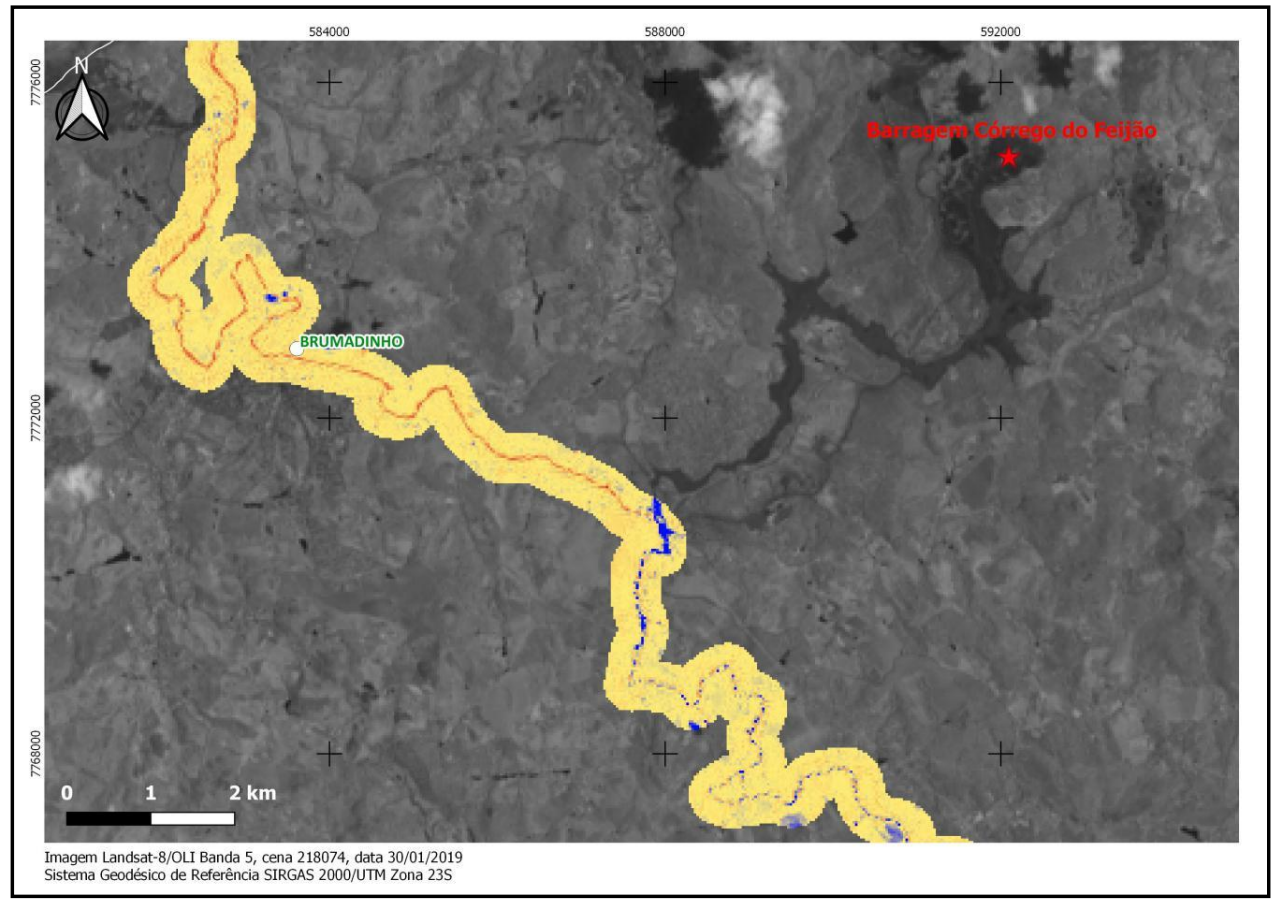

Fonte: Autores, 2019

A classificação usando a palheta de cores do software Spring foi realizada dividindo o intervalo de valores da imagem em oito classes, em que as que estão assinaladas na cor vermelha representam as maiores variações de reflectância da banda citada anteriormente para as datas escolhidas.

Dado o conhecimento de que a banda 5 do sensor OLI está posicionada na região do infravermelho próximo (851 a 879 nm), foi realizada uma correspondência entre bandas com o sensor MSI/Sentinel-2, inferindo, portanto, na banda 8 (760 a 907 nm). Desta forma, todo o procedimento metodológico foi repetido para imagens do sensor MSI/Sentinel-2, devido ao fato deste apresentar melhores resoluções espacial e temporal (figura 6).

Figura 6 - Imagem resultante após o processamento da razão de bandas uniformizadas com offset e aplicação da paleta de cores (imagem $\mathrm{S}^{\prime}$ ): na cor vermelha onde houve alterações nos constituintes opticamente ativos na água entre as datas de aquisição das imagens Sentinel-2 de 17 de janeiro e 08 de março de 2019. 


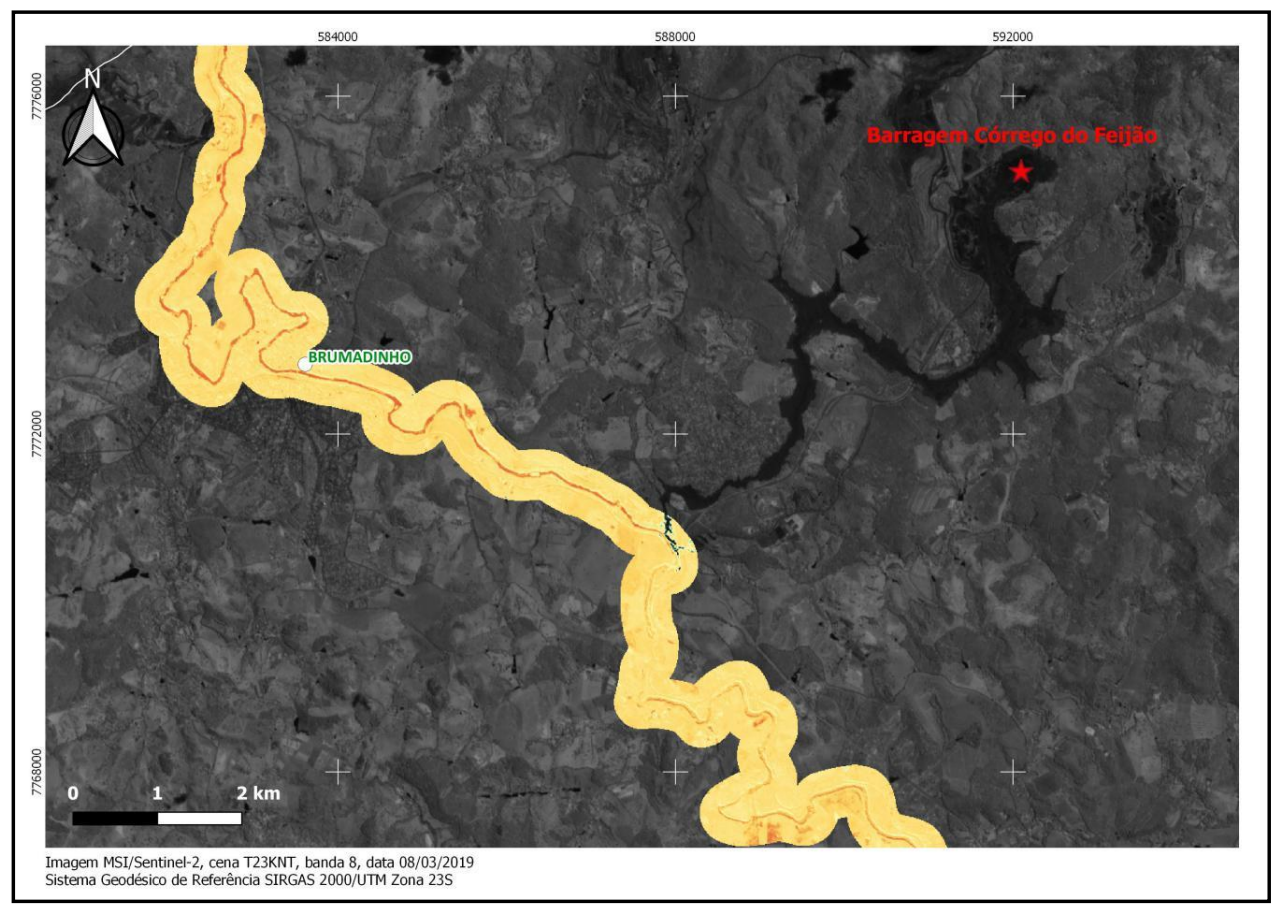

Fonte: Autores, 2019

\section{RESULTADOS}

O processamento de imagens de satélites utilizando o método da razão uniformizada entre cenas específicas e bandas espectrais selecionadas resultou numa nova imagem S" (Figura 7). Essa imagem permitiu a visualização do comportamento da variação espectral dos constituintes opticamente ativos no corpo hídrico superficial representado pelo curso do rio Paraopeba e o lago da Represa de Retiro Baixo.

Embora as águas do rio Paraopeba sejam naturalmente turvas, na data de 20 de fevereiro de 2019, 26 dias após o desastre, já era visível a alteração na cor das águas que, segundo moradores e autoridades do município de Pompéu que foram entrevistados naquela ocasião pelos autores, estavam mais "avermelhadas" que o habitual (Figura 7). Essa alteração visível na coloração das águas do rio Paraopeba se deve, provavelmente, à presença acima do esperado de óxido de ferro (Fe2O3) - um dos minérios explorados na mina e presentes na lama de rejeitos, conforme observado durante pesquisa de campo. 
Figura 7 - Fotografia do rio Paraopeba no cruzamento com a Rodovia MG-420 (19¹0'23.1"S, 44²2'04.1"W), "Ponte Pompéu”, data: 20 de fevereiro de 2019, município de Curvelo, distrito de Anguereta, MG.

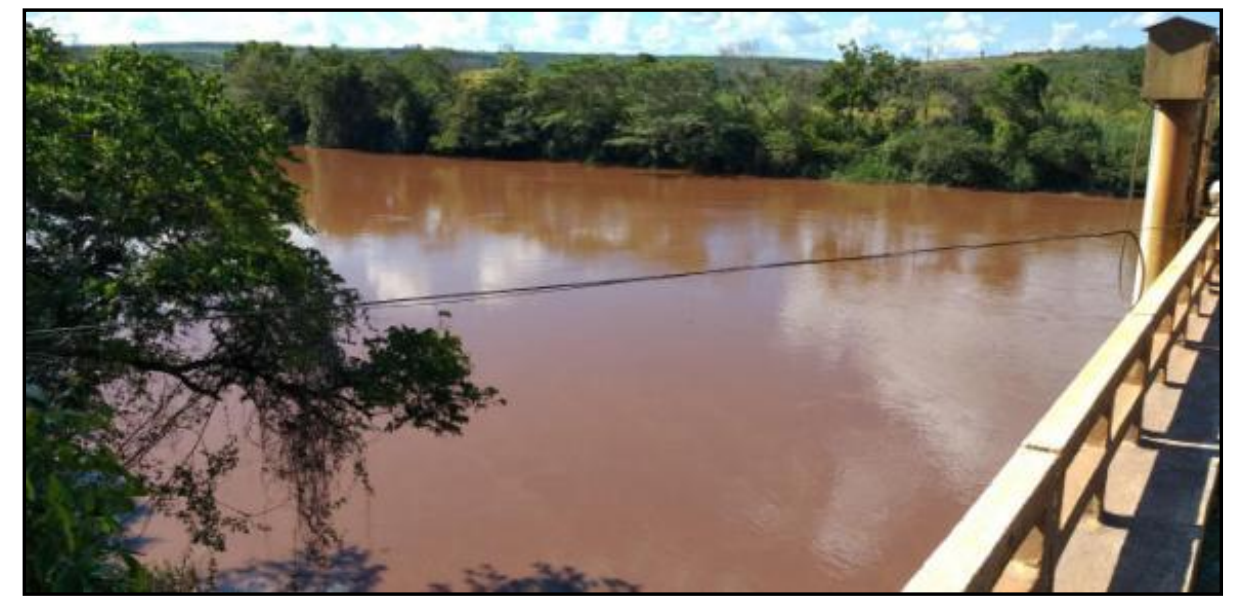

Foto: Neison Freire, 2019

Sabendo que a imagem resultante $S^{\prime \prime}$ é fruto da divisão entre a imagem de data mais antiga e a de data mais recente, torna-se possível avaliar os resultados numéricos em três situações distintas. A primeira delas diz respeito à possibilidade dos valores de reflectância do infravermelho próximo para o mesmo pixel das diferentes datas serem iguais; logo, tem-se o valor resultante igual a 1. Como as imagens resultantes receberam realce linear de contraste, com ganho igual a 100 e offset igual a 200, este valor passa, portanto, a ser 300, sendo este o valor limiar entre as variações das reflectâncias. A segunda situação se refere à quando a magnitude da reflectância da imagem de data mais recente seja maior, resultando em valores entre 0 e 1 (200 e 300, quando aplicados o mesmo ganho e offset). Por fim, a terceira situação existe quando os valores de reflectância da imagem mais antiga é maior resultando em valores maiores que 1, ou seja, maiores que 300, após aplicação de ganho e offset.

Figura 8 - (a) (esquerda) razão entre datas antes do desastre: 17 e 22 de janeiro de 2019; (b) (direita) imagem do lago da Represa de Retiro Baixo e do rio Paraopeba após o desastre com o processamento da razão de bandas uniformizadas com offset e aplicação da paleta de cores 
(imagem S"): na cor vermelha onde houve alterações nos constituintes opticamente ativos na água entre as datas de aquisição das imagens Sentinel2 de 17 de janeiro e 08 de março de 2019

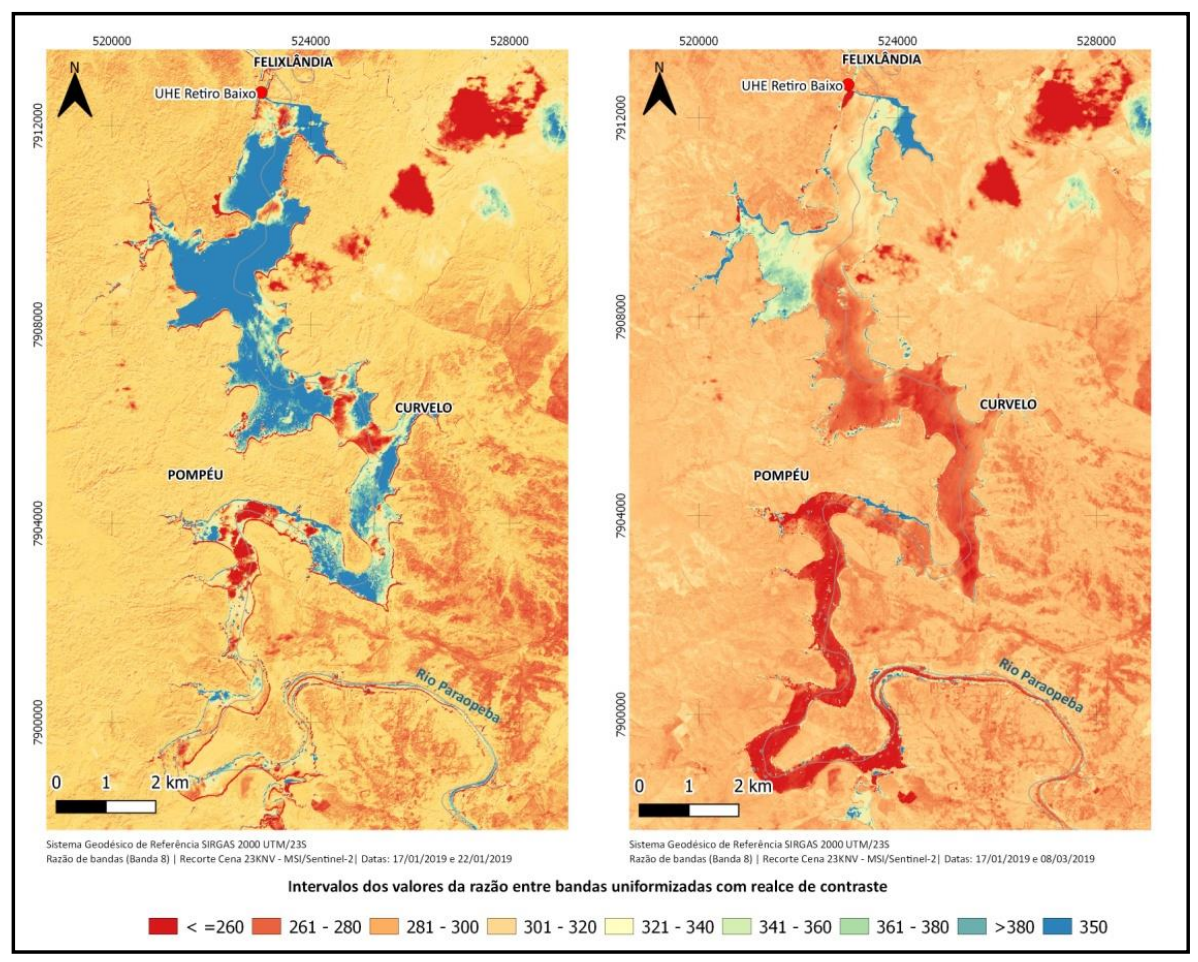

Fonte: Autores, 2019

A razão de bandas entre as datas de 17e 22 de janeiro de 2019 foi tomada como referência - uma vez que ambas as imagens são de antes do desastre - para comparação com a razão de bandas seguinte (entre as datas de 17 de janeiro e 08 de março de 2019), conforme o sensor utilizado. Aplicando a mesma paleta de cores é possível avaliar que na região referente à represa de Retiro Baixo houve um aumento significativo na reflectância do infravermelho próximo (áreas em vermelho), o que indica, portanto, seu aumento de turbidez relacionada à contaminação por rejeitos de minério. Isso é corroborado a partir da comparação com a composição colorida cor verdadeira (figura 9), permitindo a validação da metodologia e compreensão dos resultados. 
Figura 9 - (a) (esquerda): composição colorida multiespectral em cor verdadeira, RGB 432, Sentinel-2/MSI, de 17 de janeiro de 2019; (b) (direita): composição colorida multiespectral em cor verdadeira, RGB 432, Sentinel-2/MSI, de 08 de março de 2019

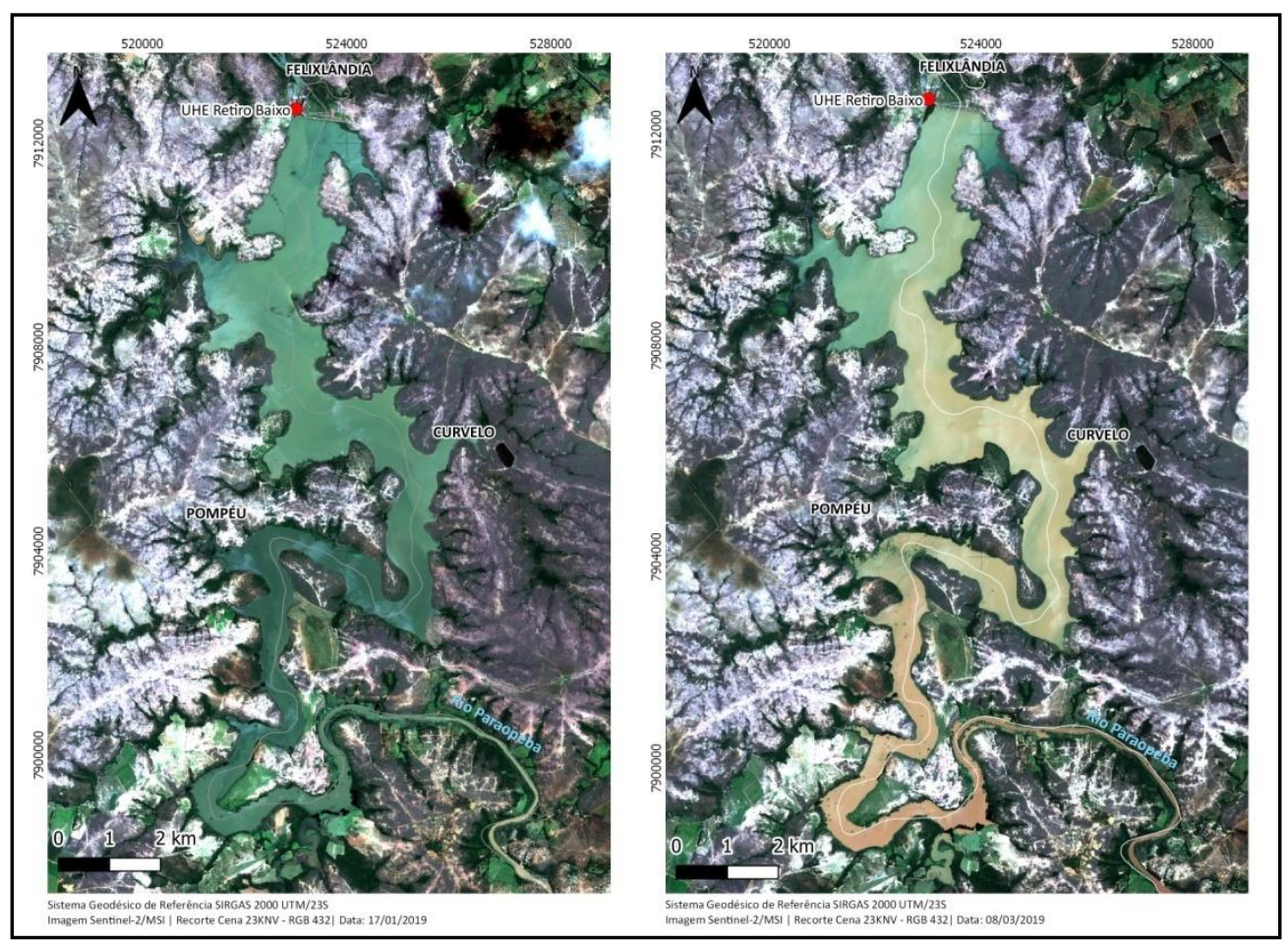

Fonte: Autores, 2019.

As estatísticas da razão de imagens podem ser observadas na tabela 1, referindose apenas aos pixels presentes no represamento da barragem de Retiro Baixo e não para todo o recorte da cena observada na figura 8. Desta forma é possível observar o deslocamento da média para valores menores que o limiar (300) o que mostra o aumento da banda do infravermelho próximo na data mais recente.

Tabela 2 - Estatísticas das imagens resultantes da razão de bandas

\begin{tabular}{lccccc}
\hline \multicolumn{2}{c}{ Razão entre imagens } & Máximo & Mínimo & Média & Desvio Padrão \\
\hline 17/jan & 22/jan & 2605,8 & 220,63 & 387,47 & 137,08 \\
17/jan & 08/mar & 1233,42 & 220,59 & 298,16 & 58,83 \\
\hline
\end{tabular}

O sucessivo processamento de imagens com a aplicação do método adotado mostrou que na data de 08 de março de 2019 o curso do rio Paraopeba, bem como a maior 
parte do lago da Represa de Retiro Baixo, apresentava sinais evidentes de alterações nos valores de reflectância de superfície do corpo hídrico quando comparado com imagens de datas recentes e anteriores ao desastre de Brumadinho. Observa-se, ainda, o comportamento peculiar do fluxo contaminante ao seguir o leito principal em direção ao barramento da UHE de Retiro Baixo. Isto pode ser notado pela linha da divisão entre municípios que segue o talvegue do rio.

Essa variação foi causada pelo processo de diluição nas águas do rio Paraopeba do material contaminante no qual se constitui a lama de rejeitos de mineração.

As cores mapeadas em vermelho nas imagens da figura 8 mostram as áreas que apresentaram aumento da concentração de constituintes opticamente ativos entre uma data e outra. A imagem (b) da figura 8, evidencia o comportamento peculiar destes constituintes, adicionados ao corpo hídrico pela lama de rejeitos através do leito principal do rio, concentrando-se ainda no canal principal e diluindo-se à medida que encontra o barramento da UHE de Retiro Baixo, ou áreas de remanso no lago de mesmo nome.

As áreas de cor azul são aquelas que apresentaram diminuição ou baixa variabilidade da turbidez entre as datas. Indicam as partes da superfície do corpo hídrico que sofreram outros processos, naturais ou antrópicos, de modificações nos seus constituintes opticamente ativos, cujas causas são exógenas ao desastre tecnoindustrial de Brumadinho. Logo, são áreas onde os parâmetros físico-químicos analíticos provavelmente apresentariam valores em conformidade com as normas de regulação oficial, caso fossem colhidas amostras da água na data recente.

A partir do processamento de imagem Sentinel-2 com aplicação desse método datada em 30 de janeiro de 2019, observou-se que a pluma de contaminação havia se deslocado pelo rio Paraopeba cerca de $40 \mathrm{~km}$ desde o ponto de contato no município de Brumadinho. Isto permite estimar sua velocidade de deslocamento em 7,84 km/dia. Após o processamento da imagem Sentinel-2 de 08 de março de 2019 da figura 8 (direita), observou-se uma diminuição dessa velocidade de deslocamento da pluma contaminante 
pelo fluxo fluvial para $7,14 \mathrm{~km} /$ dia, provavelmente em função do represamento da UHE. A partir do barramento da UHE de Retiro Baixo, a foz está na Represa de Três Marias a 27 km de distância. Imagens processadas através do método formulado referente ao dia 02 de abril de 2019 sugerem que a contaminação extravasou o barramento de Retiro Baixo e atingiu, provavelmente no dia 12 de março de 2019, a Represa de Três Marias - essa situada no próprio curso principal do rio São Francisco.

Considerando-se que a data da imagem mais antiga (17 de janeiro de 2019) se refere somente a oito dias antes do desastre (25 de janeiro de 2019), interpreta-se que essa variação espectral no corpo hídrico em tão curto período possivelmente se deve ao único evento atípico conhecido: o rompimento da barragem. Estando dentro da mesma normal climática, não se pode deduzir que fatores climáticos possam interferir significativamente nos resultados obtidos. Nesse sentido, para efeito de validação e utilizando o mesmo método, procedeu-se à razão entre bandas uniformizadas entre datas anteriores próximas ao desastre (17 e 22 de janeiro de 2019) (Figura 8, esquerda) e nenhum comportamento anômalo foi constatado semelhante ao que se observa quando se comparam imagens antes e depois do desastre. Logo, não foi a precipitação irregular do período chuvoso na região onde ocorreu o desastre a causa da variação espectral observada na imagem $\mathrm{S}^{\prime \prime}$.

Convém registrar que desde o momento da chegada da contaminação à UHE de Retiro Baixo, como a lama não foi retirada da superfície, há um fluxo contaminante constante desses rejeitos expostos ao meio natural. Esse fluxo contaminante segue pela gravidade e drenagem do terreno em direção ao ponto de contato na margem direita do rio Paraopeba, e daí para a Represa de Três Marias, passando antes pela UHE de Retiro Baixo, onde grande parte do material contaminante está se decantando no respectivo lago. Esse fluxo é originado não apenas pelo ressurgimento do Ribeirão Ferro-Carvão por cima do material depositado sobre o terreno, mas também pela erosão laminar ocasionada 
pelas chuvas concentradas e convectivas típicas da região e do período climático no qual ocorreu o desastre.

Desse modo, a pluma contaminante que chegou a Três Marias através do rio Paraopeba encontrou um corpo hídrico configurado por um sistema aquático de transição com relativas condições favoráveis de diluição, o que diminui consideravelmente a concentração dos materiais contaminantes. Nessa situação, o transporte dos componentes da água ocorre de maneira mais lenta por meio de processos convectivos e de dispersão que são misturados na coluna d'água (Barbosa et al., 2019).

\section{CONCLUSÕES}

O estudo apresentado demonstrou que há uma relação nexo-causal entre o deslocamento da lama de rejeitos e a alteração nos valores de reflectância de superfície registrados pelos sensores a bordo de satélites, cujas imagens em séries temporais processadas revelaram a extensão geográfica e a dinâmica espacial do evento até a data limite pesquisada. Além disso, mostra que a razão de bandas, técnica já muito consolidada para evidenciar determinados alvos em imagens de Sensoriamento Remoto, mostrou-se também útil para o monitoramento desta contaminação utilizando imagens de datas distintas. Entretanto, para um melhor conhecimento dos processos referentes à contaminação do rio Paraopeba, o método apresentado deve ser acrescido de outros dados georreferenciados in situ da água e suas respectivas análises. Representa, assim, uma proxy que poderá orientar a uma possível seleção de locais para um adensamento de coletas de amostras da água. Isto evidencia que o potencial do Sensoriamento Remoto em sistemas aquáticos interiores pode trazer significativas contribuições ao monitoramento geoambiental de desastres tecnoindustriais, podendo ser utilizados em conjunto com outras metodologias. Destaca-se ainda, o potencial dos softwares livres (Spring e QGIS) utilizados para o processamento de dados neste estudo. 
A partir desta pesquisa, tornou-se evidente que a contaminação chegou à Represa de Retiro Baixo até o dia 08 de março de 2019. A pluma de contaminação foi conduzida, essencialmente, pelo processo de advecção através do rio Paraopeba. Desde então, a pluma de rejeitos de mineração, que está se diluindo na massa d'água por processos simultâneos de convecção e difusão molecular, seguiu para o barramento da UHE de Três Marias e daí continuou sua trajetória de diluição pelo leito do rio São Francisco de maneira desconhecida até o momento. São também desconhecidos os valores qualiquantitativos do material exposto ao meio natural e isto impede uma melhor previsibilidade dos danos à saúde pública e ao meio ambiente, bem como o tempo de residência hidráulica dessa contaminação ao longo do rio São Francisco.

Além disso, é necessário abordar que, apesar das imagens utilizadas serem de datas próximas e terem horários de aquisição muito próximos, não foi realizado nenhum estudo sobre a posição do Sol em relação ao solo e ao satélite, o que pode ter influência sobre os resultados encontrados. Entretanto, como existiu a comparação com a composição colorida em cor verdadeira, foi possível validar o processo para este estudo.

Torna-se necessário continuar com o monitoramento geoespacial, adotando novas estratégias metodológicas e abordagens adequadas ao monitoramento, por exemplo, da contaminação nos grandes lagos do rio São Francisco. Recomenda-se, ainda, um adensamento de uma rede de coletas de dados com transmissão por telemetria em tempo real para análises constantes da qualidade da água. Evidencia-se a necessidade de uma integração entre as agendas de pesquisa das ciências sociais com as exatas e naturais, considerando-se o desafio científico representado pelo desastre tecnoindustrial de Brumadinho.

Por fim, destaca-se a contribuição metodológica que foi proposta neste artigo no sentido de auxiliar as pesquisas, estudos, planos e projetos que tenham como temática a integração entre a exploração sustentável de ativos presentes no meio ambiente e o desenvolvimento socioeconômico. Espera-se, assim, auxiliar a formulação e 
aprimoramento de políticas públicas que tenham como eixo central o desenvolvimento sustentável. Nesse aspecto, o estudo também contribuiu para a avaliação do risco associado aos desastres tecnoindustriais, nas dimensões da periculosidade, exposição e incerteza, especialmente para as populações com alta vulnerabilidade social que habitam as extensas áreas impactadas pelo desastre.

\section{REFERÊNCIAS}

BARBOSACCF, NOVO EMLM,MARTINS VS. Introdução ao Sensoriamento Remoto de Sistemas Aquáticos: princípios e aplicações. 1. Ed. [e-book]. São José dos Campos, SP: LabISA/INPE; 2019.278p.

BITENCURTI DP,MELO FP, GOIS DV, RUIZ-ESPARZA J, RIBEIRO AS, FERRARI SF, SOUZA RM Análise multitemporal do desmatamento nos municípios de Canindé de São Francisco e Poço Redondo, SE. Geosul, Florianópolis, 2017; 32(63): 117-139. Available from:

https://periodicos.ufsc.br/index.php/geosul/article/view/2177-5230.2017v32n63p117/34434 .

CATTS GP, KHORRAMS, CLOERN JE, KNIGHT AW, DEGLORIA SD. Remote sensing of tidal chlorophyll-a variations in estuaries. International Journal of Remote Sensing, 1985;6(11):1685-1706.

CHENG KS, LEITC. Reservoir Trophic state Evaluation using Landsat TM Images. Journal of the American Water Resources Association. 2001;37(5):1321-1334.

CPRM - SERVIÇO GEOLÓGICO DO BRASIL. [cited 2019 nov 27]. Monitoramento Especial do Rio Parapobela, Abril 2019. Available from:

http://www.cprm.gov.br/sace/conteudo/paraopeba/RT_01_2019_PARAOPEBA.pdf

DOÑA C, SÁNCHEZ J, CASELLES V, DOMÍNGUEZ A, CAMACHOA. Empirical Relationships for monitoring Water Quality of Lakes and Reservoirs Through Multiespectral Images. Applied Earth Observations and Remote Sensing. 2014;7(5):1632 - 1641.

DOXARAN D, FROIDEFOND J, CASTAING P,BABIN M.Dynamics of the Turbidity Maximum Zone in a Macrotidal Estuary (The Gironde, France): Observations from Field and MODIS satellite Data. Estuarine, Coastal and Shelf Science, 2009; 81(3):321 - 332.

DUANW, HE B, TAKARA K, LUO P, NOVER D, SAHU N, YAMASHIKI Y. Spatiotemporal evaluation of water quality incidents in japan between 1996 and 2007.Chemosphere.2013;93 946-953. 
ESA (European Space Agency); 2019 [cited 2019 oct 22]. Handbook Sentinel - 2. Available from: https://sentinels.copernicus.eu/web/sentinel/user-guides/document-library/-

/asset_publisher/xIslt4309D5h/content/sentinel-2-user-handbook

FERRARI JL, SANTOS AR, GARCIA RF. Análise da vegetação por meio da subtração de imagem NDVI da sub-bacia hidrográfica do córrego do Horizonte, Alegre-ES. Engenharia Ambiental - Espírito Santo do Pinhal. 2010;8(3): 3-18.

GITELSON, A. A., GAO, B. C., LI, R. R., BERDNIKOV, S., \& SAPRYGIN, V. Estimation of chlorophyll-a concentra-tion in productive turbid waters using a Hyperspectral Imager for the Coastal Oceanthe Azov Sea case study. Environmental Research Letters. 2011;6(2), 024023.

GITELSON A, GURLIN D, MOSSES W, BARROW T.A bio-optical algorithm for the remote estimation of the chrophyll-a concentration in case 2 waters. Environmental Research Letters. 2009;4(4):1-5.

HADJIMITSIS DG, CLAYTON C.Field spectroscopy forassisting water quality monitoring and assessment in watertreatment reservoirs using atmospheric corrected satellite remotely sensed imagery. Remote Sensing. 2011;3(2):362-377.

INSTITUTO MINEIRO DE GESTÃO DAS ÁGUAS (IGAM). Estudos das Metas De Qualidade Bacia Hidrográfica do Rio Paraopeba [cited 2008 sep 16]. Avaiable from:

http://aguas.igam.mg.gov.br/aguas/downloads/acordo_resultados/Estudo_Metas_Paraopeba.pdf Arquivado em 4. ago. 2007, no WaybackMachine. Acessado em 27. set. 2008.

JENSEN JR. Remote sensing of the environment: an earth resource perspective. New Jersey: Prentice Hall, 2000. 544p.

JENSEN JR. Sensoriamento do Ambiente: uma perspectiva em recursos terrestres. 2. Ed. (trad.). São José dos Campos, SP: Parêntese, 2009.

LATHROP, R. G. Landsat Thematic Mapper monitoring of turbid inland water quality. Photogrammetric Engineering and Remote Sensing.1992;58(4):465-470.

LE C, HU C,CANNIZZARO J,ENGLISH D, MULLER-KARGER F, LEE Z. Evaluation of chlorophyll-a remote sensing algorithms for an optically complex estuary. Remote Sensing of Environment. 2013;129:75-89.

LILLESAND TM, JOHNSON WL, DEUELL RL, LINDSTROM OM,MEISNER, DE. Use of Landsat data to predict the trophic state of Minnesota Lakes. Photogrammetric Engineering and Remote Sensing. 1983; 49(2): 219-229.

LIMA DL, MOTTA JS, SOUZA CA, GUERRAAPM, PARANHOS ACF.; Revisão Bibliométrica sobre Turbidez e Sólidos Suspensos por Sensoriamento Remoto. Anuário do Instituto de Geociências. 2019;42(1): 107-116. 
MAROTTA H, DOS SANTOS RO, ENRICH-PRAST A. Monitoramento limnológico: um instrumento para a conservação dos recursos hídricos no planejamento e na gestão urbano-ambientais. Ambiente \& Sociedade. 2008; 11(1): 67-79.

MARQUES JUNIOR AB, SOUZA CJS. Detecção de mudanças na cobertura vegetal, através da subtração de imagem NDVI, no Parque Estadual do Bacanga - São Luis - MA. In: XIII Simpósio Brasileiro de Sensoriamento Remoto, 13., 2007, Florianópolis. Anais. São José dos Campos. INPE, 2007. p 4013-4020.

MELO FS, SOUZA RM. Electromagnetic energy in Land area: multitemporal estimate of the albedo in Garanhuns-PE. Ciência e Natura, Santa Maria. 2016; 38(1):170 - 178.

MITTENZWEY KH, GITELSON AA, KONDRATIEV KY. Determination of Chlorophyll-a of inland waters on the basis of spectral reflectance. Limnology and Oceanography, 1992; 37(1):147-149.

NOVO EMLM, TUNDISI JG. Sensoriamento Remoto de águas interiores: perspectivas. In: Simpósio Brasileiro de Sensoriamento Remoto, 5, 1988, Natal. Anais do 5 Simpósio Brasileiro de Sensoriamento Remoto. São José dos Campos: INPE,1988; p. 13-21.

PEREIRAACF, GALO MLBT, VELINI ED. Inferência da transparência da água -reservatório de Itupararanga/SP, a partir de imagens multiespectrais IKONOS e espectro radiometria de campo. Revista Brasileira de Cartografia, 2011;63(1):179-190.

RUDORFF CM, NOVOEMLM, GALVÃO LS, PEREIRA FILHOW. Análise derivativa de dados hiperespectrais medidos em nível de campo e orbital para caracterizar a composição de águas opticamente complexas na Amazônia. Acta Amazonica, Manaus. [Internet]. 2007 June [cited 2020 Feb 04];37(2): 269-280. Available from:

http://www.scielo.br/scielo.php?script=sci_arttext\&pid=S004459672007000200014\&lng=en http://dx.doi.org/10.1590/S0044-59672007000200014

USGS (United States Geological Survey). [cited 2019 oct 22]. Handbook Landsat-8/OLI/TIRS. Available from: https://www.usgs.gov/land-resources/nli/landsat/landsat-8-data-users-handbook

ZANOTTA DC, FERREIRA MP, ZORTEA M. Processamento de Imagens de Satélite. São Paulo, SP: Oficina de Textos, 2019.

\section{CONTRIBUIÇÕES DE AUTORIA}

\section{1 - Neison Cabral Ferreira Freire}

Fundação Joaquim Nabuco, Pesquisador Titular

https://orcid.org/0000-0003-0153-8964 - neison.freire@fundaj.gov.br 
Contribuição: Coordenador da pesquisa, definição da metodologia em Sensoriamento Remoto, programação de álgebra espacial e pesquisa de campo.

\section{2 - Admilson da Penha Pacheco}

Universidade Federal de Pernambuco, Professor Titular

https://orcid.org/0000-0002-3635-827X - pacheco3p@gmail.com

Contribuição: Revisão de literatura em Sensoriamento Remoto, ajustes metodológicos

\section{3 - Vinícius D'Lucas Bezerra Queiroz}

Universidade Federal de Pernambuco, Engenheiro Cartógrafo e Agrimensor

https://orcid.org/0000-0002-9767-9982 - vinicius.dlucas@gmail.com

Contribuição: Processamento das imagens de satélites, revisão de literatura em Sensoriamento Remoto, programação de álgebra espacial e confecção de cartas-imagem.

\section{COMO CITAR ESTE ARTIGO}

FREIRE, N. C. F.; PACHECO, A. P.; QUEIROZ, V. D. B. Uma abordagem metodológica de Sensoriamento Remoto para o monitoramento da contaminação do rio Paraopeba pósdesastre de Brumadinho-MG. Ciência e Natura, Santa Maria, v. 43, e36, p. 1-30, 2021. Disponível em: https://doi.org/10.5902/2179460X43632. Acesso em: dia, mês (abreviado), ano. 